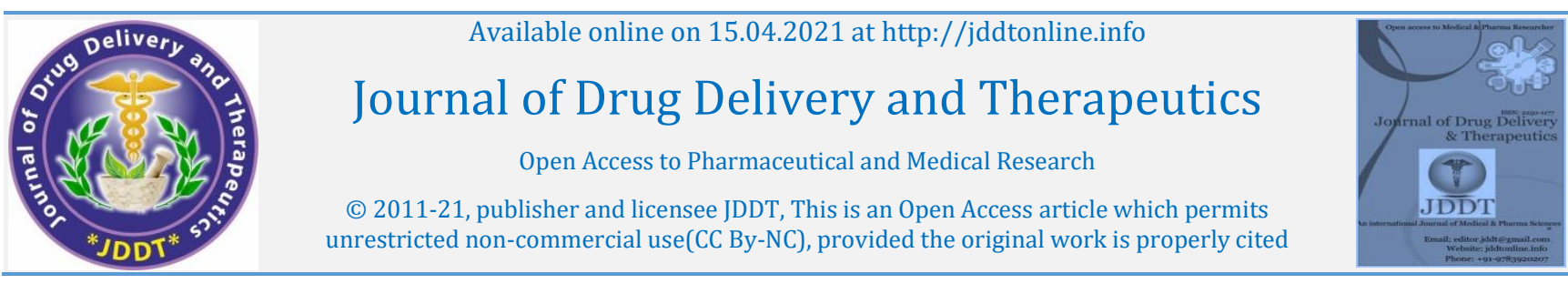

(C) 2011-21, publisher and licensee JDDT, This is an Open Access article which permits Open Access Full Text Article

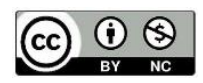

Review Paper

\title{
A Review of the Pharmacological Characteristics of Vanillic Acid
}

\author{
Ashwini S. Ingole, Megha P. Kadam, Aishwarya P. Dalu, Shital M. Kute, Piyusha R. Mange, Vaishali D. Theng, \\ Om R. Lahane, Aniket P. Nikas, Yash V. Kawal, Shatrughna U. Nagrik, Prashant A. Patil
}

Gawande College of Pharmacy, Sakharkherda (MH), India

\begin{tabular}{ll}
\hline Article Info: & \\
\hline$\square$ & Article History: \\
\hline & Received 13 Feb 2021 \\
& Accepted 05 April 2021 \\
& Available online 15 April 2021
\end{tabular}

*Address for Correspondence:

Ashwini S. Ingole, Gawande College of Pharmacy, Sakharkherda, (MH), India

\section{Abstract}

A dihydroxybenzoic acid analog used as a flavoring agent is vanillic acid (4hydroxy-3methoxybenzoic acid). It's a form of vanillin that has been oxidized. It's also a step in the process of making vanillin from Ferulic Acid. Vanillic acid has seen a lot of press because of its many uses in the cosmetics, fruit, flavorings, cigarettes,alcohols, drinks, and polymer sectors. It's said to have effective antioxidant, anti-inflammatory, and neuroprotective properties. The pharmacological impact on oxidative stress-induced neuro-degeneration, on the other hand, have not been thoroughly examined. The pharmacological properties of vanillic Acid lead to its possible use in the treatment of various diseases.

Keywords: Vanillic acid, Pharmacological Potential, wound healing, Antioxidants

Cite this article as:

Ingole AS, Kadam MP, Dalu AP, Kute SM, Mange PR, Theng VD, Lahane OR, Nikas AP, Kawal YV, Nagrik SU, Patil PA, A Review of the Pharmacological Characteristics of Vanillic Acid, Journal of Drug Delivery and Therapeutics. 2021; 11(2-s):200-204 D0I: http://dx.doi.org/10.22270/jddt.v11i2-s.4823

\section{INTRODUCTION}

Vanilla beans contain the largest concentration of vanillic acid (4-hydroxy-3-methoxybenzoic acid). It can be present in a variety of species, including the Chinese medicinal plant Angelica sinensis, benzoin, soybeans, olives, among many others. ${ }^{1}$ It occurs as a white/yellow powder or crystals with a good creamy odor, and is thus used as a fragrance and flavoring agent. ${ }^{2}$ Natural vanillic acid can be found in a variety of foods, including oranges, guava, sherry, rice grains, brandy, bourbon, scotch, and Canadian whisky, as well as red and white wines. Vanillic acid has seen a lot of press because of its many uses in the cosmetics, fruit, flavorings, cigarettes, pharma, alcohols, drinks, and polymer sectors. However, separating it from fermentation broths and wastewater from olive oil mills, as well as the paper and pulp industries, remains a difficult task. 3 The isolation of vanillic acid from aqueous sources was studied in this paper using liquid-liquid extraction. Calculating the partition coefficient, dimerization constant, distribution coefficient, and extraction efficiency are used to determine equilibrium. 4 The extraction ability is given in terms of extraction efficiency and distribution coefficient followed a trend:1octanol $(54.07 \%)>$ isobutanol $(51.73 \%)>$ toluene $(45.23 \%)$ $>$ xylenes $\operatorname{mix}(35.47 \%)>$ petroleum ether $(31.54 \%)>$ benzene $(30.44 \%)$. The obtained results were discussed with help of acid properties, type of solvent used, and their physicochemical properties such as dipole moment (Dm), dielectric constant $(\varepsilon)$, solvent polarity parameter (ET), solubility in water, octanol-water partition coefficient (log Kow), etc. 5 This is the first research to use the extractive separation approach to isolate or recover vanillic acid from aqueous solutions using the solvents described above. 6

\section{PHARMACOLOGICAL ACTION}

\subsection{Sedative activity:}

The ethanol extract of Vernonia patula (VP) aerial parts demonstrated strong antinociceptive behavior when examined in acetic acid-induced writhing and formalininduced paw-licking experiments. 7 It also significantly delayed the onset of sleep, increased the length of sleeping time, and significantly decreased locomotor activity and exploratory behavior in mice in neuropharmacological studies. 8 Following HPLC-DAD study, five phenolic compounds were found in VP: gallic acid, vanillic acid, caffeic acid, quercetin, and kaempferol. The presence of these phenolic compounds in VP lends credence to the antinociceptive and sedative effects observed. 9 The cannabinoid type 1 (CB1) receptor binding affinity of gallic acid, vanillic acid, caffeic acid, quercetin, and kaempferol was predicted using a statistical analysis. ${ }^{10}$ The most likely ligand efficiency indices against the CB1 target is caffeic and vanillic acid. Vanillic acid has the highest estimation score for blood-brain barrier penetration. These results support the long-held belief that VP can be used to relieve pain. ${ }^{11}$

\subsection{Antidepressant effects:}

Depression is a common psychological ailment that affects up to $20 \%$ of the global population. Traditional Chinese medicine (TCM), with its unusual curative role in the treatment of depression, is gaining popularity as pharmaceutical firms rush to produce new antidepressant drugs. 12 This article reviews studies on TCM natural products that have been reported to have antidepressant effects in the last two decades, and which can be categorized 
based on different pathways such as increasing monoamine synaptic concentrations, alleviating hypothalamic-pituitaryadrenal (HPA) axis dysfunctions, decreasing neuroplasticity impairment, and battling depression. ${ }^{13}$ Saponins, flavonoids, alkaloids, polysaccharides, and other antidepressant active ingredients have all been reported. ${ }^{14}$ Albiflorin, Baicalein, Berberine chloride, beta-Asarone, cannabidiol, Curcumin, Daidzein, Echinocystic acid (EA), Emodin, Ferulic acid, Gastrodin, Genistein, Ginsenoside Rb1, Ginsenoside Rg1, Ginsenoside Rg3, Hederagenin, Hesperidin, Honokiol, Hyperoside, Icariin, Isoliquiritin, Kaempferol, Liquiritin, Ltheanine, Magnolol, Paeoniflorin, Piperine, Proanthocyanidin, Puerarin, Quercetin, Resveratrol (trans), Rosmarinic acid, Saikosaponin A, Senegenin,
Tetrahydroxystilbene glucoside and Vanillic acid are Specified in this review. Simultaneously, chemical structures of the active ingredients with antidepressant activities are listed and their sources, models, efficacy and mechanisms are described.15 Antidepressant Chinese compound prescriptions and extracts are now added, which may serve as a source of inspiration for future study. ${ }^{16}$ According to the findings of this review, some TCMs have an antidepressant effect that is positive and motivating. However, much work continues to be done in order to ascertain the precise medicinal effects and pathways of certain active ingredients, especially in order to create a unified standard for diagnosis and assessment of curative action. ${ }^{17}$

Table 1: Plant Contain Vallinic Acid and Its Reported Activity

\begin{tabular}{|c|c|c|c|c|c|c|}
\hline Sr.No & Activity & Plant Name & family & Extract of plant & $\begin{array}{l}\text { Part of } \\
\text { plant }\end{array}$ & Reference \\
\hline 1 & Sedative activity & Vernonia patula & Asteraceae & Ethanol extract & Aerial part & {$[7][8][9][1][11]$} \\
\hline 2 & $\begin{array}{l}\text { Antidepressant } \\
\text { effects }\end{array}$ & Panax ginseng & Araliaceae & $\begin{array}{l}\text { methanolic } \\
\text { extracts }\end{array}$ & Root & {$[12][13][14][15][16][17]$} \\
\hline 3 & $\begin{array}{l}\text { Antinociceptive } \\
\text { effects }\end{array}$ & Lithraea molleoides & Anacardiaceae & $\begin{array}{l}\text { Dichloromethane } \\
\text { extract }\end{array}$ & $\begin{array}{l}\text { Leaves,bud,\& } \\
\text { Stems }\end{array}$ & $\begin{array}{l}{[18][19][20][21][22]} \\
{[23]}\end{array}$ \\
\hline 4 & Hypertension & Angelica sinensis & Apiaceae & $\begin{array}{l}\text { ethyl acetate } \\
\text { extract }\end{array}$ & Root & {$[24][25][26][27][28]$} \\
\hline 5 & $\begin{array}{l}\text { ulcerative colitis } \\
\text { effects }\end{array}$ & Angelica sinensis & Apiaceae & $\begin{array}{l}\text { ethyl acetate } \\
\text { extract }\end{array}$ & Root & [29][30][31][32] \\
\hline 6 & Anticancer effects & Camellia sinensis & Theaceae & Ethanol extract & Leaves & {$[33][34][35][36][37]$} \\
\hline 7 & $\begin{array}{l}\text { Antifungal } \\
\text { activities }\end{array}$ & $\begin{array}{l}\text { Thecacoris } \\
\text { annobonae Pax }\end{array}$ & Phyllanthaceae & methanol extract & Stems bark & {$[38][39][40]$} \\
\hline 8 & $\begin{array}{l}\text { Hepatoprotective } \\
\text { activity }\end{array}$ & Lentinula edodes & Marasmiaceae & seed extracts & Whole plant & {$[41][42][43][44][45]$} \\
\hline 9 & $\begin{array}{l}\text { Wound healing } \\
\text { activity }\end{array}$ & Panax ginseng & Araliaceae & $\begin{array}{l}\text { methanolic } \\
\text { extracts }\end{array}$ & Root & [46][47] \\
\hline 10 & $\begin{array}{l}\text { Antioxidant } \\
\text { activity }\end{array}$ & $\begin{array}{l}\text { Cyathobasis } \\
\text { fruticulosa }\end{array}$ & Amaranthaceae & methanol extract & Plant tissues & {$[48][49][50][51][52]$} \\
\hline
\end{tabular}

\subsection{Antinociceptive effects:}

Many plants used in herbal medicine contain high levels of vanillic acid. It has been linked to a number of pharmacologic effects, including carcinogenesis inhibition, apoptosis, and inflammation, but it is well known for its pleasant creamy odor. ${ }^{18}$ Since there are few studies on this phenolic compound's antinociceptive function, the aim of this research was to investigate it in invivo animal models. ${ }^{19}$ The intraperitoneal administration of vanillic acid resulted in dose-dependent suppression of the acetic acid-induced writhing reaction (ED50:9.3mg/kg). ${ }^{20}$ Pretreatment with ondansetron and yohimbine inhibited the antinociceptive function, suggesting that the serotonin ergicandad renergicsy stems could be involved in the pathway underlying vanillic acid's analgesic activity. ${ }^{21}$ In vivo, this compound was shown to interact with ASICs (Acid-sensing Ion Channels) as well as TPRV1, TRPA1, and TRPM8 receptors. Additionally, vanillic acid has little effect on locomotory activity or muscle control. 22 The $t 1 / 2$ and AUC of plasmatic phenolic content were 0.123 and $1.38 \mathrm{~g} \cdot \mathrm{h} / \mathrm{mL}$, respectively, as determined by HPLC. Finally, vanillic acid could be a promising medicinal alternative for the management of pain. ${ }^{23}$

\subsection{Hypertension:}

In adult male albino Wistar rats treated with N-Nitro-Larginine methyl ester hydrochloride (L-NAME), the antihypertensive and antioxidant ability of vanillic acid (VA) was examined. ${ }^{24}$ In contrast to the control group, rats given L-NAME ( $40 \mathrm{mg} / \mathrm{kg}$ Bw for 30 days) had a persistent rise in systolic (SBP) and diastolic (DBP) blood pressure, as well as a substantial decrease in nitrite/nitrate (NOx) concentration in plasma. 25 SBP and DBP in rats treated with VA were restored to normal levels, although plasma NO metabolites concentrations were maintained. Furthermore, VA greatly recovered enzymatic antioxidants (superoxide dismutase, catalase, and glutathione peroxidase), non-enzymatic antioxidants (vitamin C, vitamin E), and lipid peroxidation products (thiobarbituric acid reactive compounds, lipid hydroperoxides, conjugated dienes). ${ }^{26}$ Hepatic and renal function indicators were assessed to see if VA therapy caused any toxicity. The effect of $50 \mathrm{mg} / \mathrm{kg}$ Bw VA was more pronounced than the other two doses, 25 and $100 \mathrm{mg} / \mathrm{kg}$ 
Bw, according to our findings. (\#27) Hepatic and renal function indicators were assessed to see if VA therapy caused any toxicity. The effect of $50 \mathrm{mg} / \mathrm{kg} \mathrm{Bw}$ VA was more pronounced than the other two doses, 25 and $100 \mathrm{mg} / \mathrm{kg}$ Bw, according to our findings. ${ }^{27}$ Histopathology research backed up these findings. In L-NAME-induced hypertensive rats, VA has antihypertensive and antioxidant properties. ${ }^{28}$

\subsection{Ulcerative colitis effects:}

Vanillic acid is a benzoic acid derivative that is used as a flavoring agent. It is an oxidized form of vanillin. The aim was to see if vanillic acid could help people with ulcerative colitis caused by dextran sulfate sodium (DSS). ${ }^{29}$ Our findings revealed that vanillic acid decreased the severity of DSS-induced colitis clinical symptoms, such as weight loss and colon length shortening, as well as the disease activity index. Vanillic acid inhibited the expression of cyclooxygenase- 2 and the activation of transcription nuclear factor-B p65 in DSS-treated colon tissues, according to the findings. ${ }^{30}$ Furthermore, plasma levels of interleukin (IL) -6 were higher in the DSS-treated group than in the control group, but these higher levels were decreased by vanillic acid administration. ${ }^{31}$ These results indicate that vanillic acid has a protective effect against DSS-induced ulcerative colitis, suggesting its utility in the management of chronic intestinal inflammation. 32

\subsection{Anticancer effects:}

Hypoxia-inducible factor 1 (HIF-1) is a significant factor in tumor tolerance to microenvironmental hypoxia, as well as angiogenesis and tumor growth. ${ }^{33}$ Vanillic acid is a phenolic compound found in foods that has been shown to have anticancer properties. The mechanisms by which vanillic acid inhibits tumor development, however, remain unknown. The effect of vanillic acid on HIF-1 activation was investigated in this study. ${ }^{34}$ In different human cancer cell lines, vanillic acid inhibits HIF-1 expression caused by hypoxia. Vanillic acid prevented the synthesis of HIF-1 protein, according to further research. Vanillic acid had no effect on the rate of HIF-1 protein degradation or the steadystate levels of HIF-1 mRNA. ${ }^{35}$ Vanillic acid also inhibited HIF-1 expression by suppressing the rapamycin/p70 ribosomal protein $\mathrm{S} 6$ kinase/eukaryotic initiation factor 4Ebinding protein-1 and Raf/extracellular signal-regulated kinase (ERK) kinase (MEK) kinase (ERK) kinase (MEK) kinase (ERK) kinase (ERK Vanillic acid inhibited VEGF and EPO protein expression and disrupted tube formation in a dose-dependent manner, according to our findings. 36 The findings indicate that vanillic acid prevents angiogenesis effectively. Vanillic acid significantly induced G1 phase arrest and prevented the proliferation of human colon cancer HCT116 cells, according to flow cytometry study. Vanillic acid therapy inhibited tumor growth substantially in a xenografted tumor model, according to in vivo studies. These findings show that vanillic acid is an important HIF-1 inhibitor and shed light on the mechanism of its antitumor activity. 37

\subsection{Antifungal activities:-}

Mitsunobu technique was used to synthesize four castor oil fatty acid-based novel lipoconjugates of phenolic acids. The phenolic moieties are ferulic and vanillic acid, and the lipid component is made up of methyl ricinoleate and its saturated analogue, methyl-12-hydroxystearate .38 Synthetic compounds are compared to three commonly used antioxidants in the food industry, BHT, atocopherol, and dodecyl gallate, in three in vitro assays (DPPH radical scavenging assay, DSC tests for oxidative induction temperature of linoleic acid, and autoxidation of linoleic acid in Tween 20 micellar medium). ${ }^{39}$ The antiradical activity of synthesised compounds has been discovered to be very good. These compounds also had a lot of antifungal activity against the fungal strains that were tested. All of these findings indicated that the synthesized compounds could be used as effective lipophilic antioxidants in the fight against oxidative stress. 40

\subsection{Hepatoprotective activity:-}

The edible mushroom Lentinula edodes' mycelia can be cultured in lignin-rich solid medium, and the hot-water extracts (L.E.M.) are commercially available as a dietary supplement. During cultivation, the lignin-degrading peroxidase secreted by L. edodes mycelia formed phenolic compounds such as syringic acid and vanillic acid. 41 We investigated their protective effect on oxidative stress in mice with CCl4-induced liver injury because these compounds have radical scavenging activity. On CCl4induced chronic liver injury in mice, the hepatoprotective effects of syringic acid and vanillic acid were investigated. 42 The serum levels of aspartate aminotransferase (AST) and alanine aminotransferase (ALT) increased after $\mathrm{CCl} 4$ was injected into the peritoneal cavity. The levels of transaminases were substantially reduced when syringic acid and vanillic acid were administered intravenously. Four weeks of CCl4 therapy resulted in a reasonable amount of collagen fibril deposition. ${ }^{43}$ Syringic acid and vanillic acid clearly suppressed collagen aggregation and significantly decreased hepatic hydroxyproline content, which is a quantitative marker of fibrosis, according to Azan-stained liver parts. ${ }^{44}$ Both of these compounds held hepatocyte viability while inhibiting the activation of cultured hepatic stellate cells, which play a key role in liver fibrogenesis. These results indicate that syringic and vanillic acid administration may minimize hepatic fibrosis in chronic liver injury. 45

\subsection{Wound healing activity:}

Skin care products containing Panax ginseng C.A. Meyer are commonly used. The phenolic acids in ginseng root extract (GRE) have been shown to inhibit melanogenesis in a previous study. Vanillic acid, the most abundant portion of phenolic acids in GRE, suppressed the expression of microphthalmia-associated transcription factor (MITF) and melanogenic enzyme sinB16F10 cells and decreased tyrosinase activity and melanin levels with or without -MSH stimulation. ${ }^{46}$ NOS activity, nitricoxide (NO) content, cGMP level, guanylate cyclase (GC) and protein kinase G (PKG) activity, and the phosphorylation of cAMP-response element-binding protein (CREB) were all reduced by vanillic acid, while arbutin had no effect on the NO/PKG pathway. These findings suggest that vanillic acid in GRE inhibited the NO/PKG signaling pathways, thus suppressing melanogenesis. This research reveals a possible mechanism for ginseng's melanogenesis inhibitory effect. 47

\subsection{Antioxidant activity:}

Diabetes has become much more common across the world as a result of widespread behavioral and dietary changes. In humans and animals, high-fat diets are closely linked to the development of obesity and can cause insulin resistance. 48 Obesity is undeniably a risk factor for the onset of type 2 diabetes. Using a rat model, we explored the therapeutic potential of vanillic acid on diabetes-related complications in this report. Rats were given a high fat diet (HFD) for 20 weeks and then given vanillic acid ( $50 \mathrm{mg} / \mathrm{kg} \mathrm{bw}$ ) for the last eight weeks to make them diabetic and hypertensive. 49 The effects of vanillic acid on glucose, plasma insulin, systolic and diastolic blood pressure, thiobarbituric acid 
reactive substances (TBARS), hydroperoxides as a lipid peroxidation marker, and the activities of superoxide dismutase (SOD), catalase (CAT), glutathione peroxidase (GPx), reduced glutathione (GSH), vitamin $\mathrm{C}$ and vitamin $\mathrm{E}$ as an antioxidant marker, AST and ALT as a liver function marker, urea, uric acid and creatinine as a kidney function marker were investigated. 50 The histopathology of the liver and kidney was also looked at as part of the diabetes pathology. When diabetic rats were given oral vanillic acid at a dosage of $50 \mathrm{mg} \mathrm{kg} /$ body weight for 8 weeks, their fasting plasma glucose, insulin, and blood pressure levels were significantly lower than in the diabetic control group. ${ }^{51}$ In diabetic hypertensive rats treated with vanillic acid antioxidant activities were significantly improved and lipid peroxidation markers were significantly reduced. These findings indicate that vanillic acid has a modulatory impact on diabetic hypertension regulation by lowering blood glucose, insulin, and blood pressure while also combating oxidative stress via tissue activation. ${ }^{52}$

\section{CONCLUSION}

In the treatment of vascular dementia and cerebrovascular insufficiency states, vanillic acid is a promising, affordable, and novel neuroprotective agent. It has recently been the focus of extensive studies, and it has shown its effectiveness as a pharmacotherapeutic agent in a variety of diseases. Aside from the antioxidant action of the majority of compounds in the vanillic acid class, i.e. phenolic compounds, it has also been stated to function at the molecular level. Vanillic acid is an excellent candidate for more systematic and detailed analysis. It may be a potential treatment option for a variety of severe diseases.

\section{REFERENCES}

1] Dandekar P, Wasewar KL. Experimental investigation on extractive separation of vanillic acid. Chemical Data Collections. 2020 Dec 1; 30:100564

2] Wang J, Fung DY. Alkaline-fermented foods: a review with emphasis on pidan fermentation. Critical Reviews in Microbiology. 1996 Jan 1; 22(2):101-38.

3] Ignat I, Volf I, Popa VI. A critical review of methods for characterisation of polyphenolic compounds in fruits and vegetables. Food chemistry. 2011 Jun 15; 126(4):1821-35.

4] Antony FM, Wasewar KL. Reactive separation of protocatechuic acid using tri-n-octyl amine and di-(2-ethylhexyl) phosphoric acid in methyl isobutyl ketone. Separation and Purification Technology. 2018 Dec 22; 207:99-107.

5] Prince PS, Rajakumar S, Dhanasekar K. Protective effects of vanillic acid on electrocardiogram, lipid peroxidation, antioxidants, proinflammatory markers and histopathology in isoproterenol induced cardiotoxic rats. European journal of pharmacology. 2011 Oct 1; 668(1-2):233-40.

6] Onofrejová L, Vašíčková J, Klejdus B, Stratil P, Mišurcová L, Kráčmar S, Kopecký J, Vacek J. Bioactive phenols in algae: The application of pressurized-liquid and solid-phase extraction techniques. Journal of pharmaceutical and biomedical analysis. 2010 Jan 20; 51(2):464-70.

7] Siraj MA, Howlader MS, Rahaman MS, Shilpi JA, Seidel V. Antinociceptive and sedative activity of Vernonia patula and predictive interactions of its phenolic compounds with the cannabinoid type 1 receptor. Phytotherapy Research. 2021 Feb; 35(2):1069-79.

8] Rahman M, Khatun A, Nesa M, Hossain H, Jahan IA. Bioactive polyphenols from the methanol extract of Cnicus arvensis (L.) Roth demonstrated antinociceptive and central nervous system depressant activities in mice. Evidence-Based Complementary and Alternative Medicine. 2015 Jan 1; 2015.

9] Guimarães R, Barros L, Dueñas M, Carvalho AM, Queiroz MJ, Santos-Buelga C, Ferreira IC. Characterisation of phenolic compounds in wild fruits from Northeastern Portugal. Food Chemistry. 2013 Dec 15; 141(4):3721-30.

10] Khatun A, Rahman M, Rahman M, Hossain H, Jahan IA, Nesa M. Antioxidant, antinociceptive and CNS activities of Viscum orientale and high sensitive quantification of bioactive polyphenols by UPLC. Frontiers in pharmacology. 2016 Jun 29; 7:176.

11] Swiss Academy of Medical Sciences, Swiss Academy of Sciences. Ethical principles and guidelines for experiments on animals. Experientia. 1993 Jan; 49:1-3.

12] Wang YS, Shen CY, Jiang JG. Antidepressant active ingredients from herbs and nutraceuticals used in TCM: pharmacological mechanisms and prospects for drug discovery. Pharmacological research. 2019 Dec 1; 150:104520.

13] Guo $F$, Tang $X$, Zhang $W$, Wei J, Tang $S$, Wu $H$, Yang $H$. Exploration of the mechanism of traditional Chinese medicine by AI approach using unsupervised machine learning for cellular functional similarity of compounds in heterogeneous networks, XiaoErFuPi granules as an example. Pharmacological Research. 2020 Oct 1; 160:105077.

14] Wills RB, Bone $K$, Morgan $M$. Herbal products: active constituents, modes of action and quality control. Nutrition research reviews. 2000 Jun; 13(1):47-77.

15] Xiang H, Liu Y, Zhang B, Huang J, Li Y, Yang B, Huang Z, Xiang F, Zhang $\mathrm{H}$. The antidepressant effects and mechanism of action of total saponins from the caudexes and leaves of Panax notoginseng in animal models of depression. Phytomedicine. 2011 Jun 15; 18(8-9):731-8.

16] Hayashi T, Tsai SY, Mori T, Fujimoto M, Su TP. Targeting ligandoperated chaperone sigma-1 receptors in the treatment of neuropsychiatric disorders. Expert opinion on therapeutic targets. 2011 May 1; 15(5):557-77.

17] Kim Y, Lee HY, Choi YJ, Cho SH. Antidepressant effects of ginsenoside Rf on behavioral change in the glial degeneration model of depression by reversing glial loss. Journal of Ginseng Research. 2020 Jul 1; 44(4):603-10.

18] Kakkar S, Bais S. A review on protocatechuic acid and its pharmacological potential. International Scholarly Research Notices. 2014; 2014.

19] Gorzalczany S, Marrassini C, Miño J, Acevedo C, Ferraro G. Antinociceptive activity of ethanolic extract and isolated compounds of Urtica circularis. Journal of ethnopharmacology. 2011 Apr 12; 134(3):733-8.

20] Chuang HW, Wei IH, Lin FY, Li CT, Chen KT, Tsai MH, Huang CC. Roles of Akt and ERK in mTOR-Dependent Antidepressant Effects of Vanillic Acid. ACS omega. 2020 Feb 13; 5(7):3709-16.

21] Khoshnam SE, Sarkaki A, Khorsandi L, Winlow W, Badavi M, Moghaddam HF, Farbood Y. Vanillic acid attenuates effects of transient bilateral common carotid occlusion and reperfusion in rats. Biomedicine \& Pharmacotherapy. 2017 Dec 1; 96:667-74.

22] de los Angeles Yrbas M, Morucci F, Alonso R, Gorzalczany S. Pharmacological mechanism underlying the antinociceptive activity of vanillic acid. Pharmacology Biochemistry and Behavior. 2015 May 1; 132:88-95.

23] Morucci F, Lopez P, Miño J, Ferraro G, Gorzalczany S. Antinociceptive activity of aqueous extract and isolated compounds of Lithrea molleoides. Journal of ethnopharmacology. 2012 Jul 13; 142(2):401-6.

24] Kumar S, Prahalathan P, Raja B. Antihypertensive and antioxidant potential of vanillic acid, a phenolic compound in $\mathrm{L}-$ NAME-induced hypertensive rats: a dose-dependence study. Redox Report. 2011 Sep 1; 16(5):208-15.

25] Saravanakumar M, Raja B, Manivannan J, Silambarasan $T$, Prahalathan P, Kumar S, Mishra SK. Oral administration of veratric acid, a constituent of vegetables and fruits, prevents cardiovascular remodelling in hypertensive rats: a functional evaluation. British Journal of Nutrition. 2015 Nov; 114(9):138594.

26] Raja B, Saravanakumar M, Sathya G. Veratric acid ameliorates hyperlipidemia and oxidative stress in Wistar rats fed an atherogenic diet. Molecular and cellular biochemistry. 2012 Jul; 366(1):21-30

27] Shakeel M, Jabeen F, Qureshi NA, Fakhr-e-Alam M. Toxic effects of titanium dioxide nanoparticles and titanium dioxide bulk salt in the liver and blood of male Sprague-Dawley rats assessed by different assays. Biological trace element research. 2016 Oct; 173(2):405-26.

28] Robles-Vera I, Toral M, Romero M, Jiménez R, Sánchez M, PérezVizcaíno F, Duarte J. Antihypertensive effects of probiotics. Current hypertension reports. 2017 Apr 1; 19(4):26.

29] Kim SJ, Kim MC, Um JY, Hong SH. The beneficial effect of vanillic acid on ulcerative colitis. Molecules. 2010 Oct; 15(10):7208-17. 
30] Wang K, Jin X, Li Q, Sawaya AC, Le Leu RK, Conlon MA, Wu L, Hu F. Propolis from different geographic origins decreases intestinal inflammation and Bacteroides spp. populations in a model of DSS-Induced colitis. Molecular Nutrition \& Food Research. 2018 Sep; 62(17):1800080.

31] Larrosa M, Luceri C, Vivoli E, Pagliuca C, Lodovici M, Moneti G, Dolara P. Polyphenol metabolites from colonic microbiota exert anti-inflammatory activity on different inflammation models. Molecular nutrition \& food research. 2009 Aug; 53(8):1044-54.

32] Somani SJ, Modi KP, Majumdar AS, Sadarani BN. Phytochemicals and their potential usefulness in inflammatory bowel disease. Phytotherapy research. 2015 Mar; 29(3):339-50.

33] Lee JW, Bae SH, Jeong JW, Kim SH, Kim KW. Hypoxia-inducible factor (HIF-1) $\alpha$ : its protein stability and biological functions. Experimental \& molecular medicine. 2004 Feb; 36(1):1-2.

34] Gong J, Zhou S, Yang S. Vanillic acid suppresses HIF-1 $\alpha$ expression via inhibition of mTOR/p70S6K/4E-BP1 and Raf/MEK/ERK pathways in human colon cancer HCT116 cells. International journal of molecular sciences. 2019 Jan; $20(3): 465$.

35] Tang XD, Zhou X, Zhou KY. Dauricine inhibits insulin-like growth factor-I-induced hypoxia inducible factor $1 \alpha$ protein accumulation and vascular endothelial growth factor expression in human breast cancer cells. Acta Pharmacologica Sinica. 2009 May; 30(5):605-16.

36] Velli SK, Sundaram J, Murugan M, Balaraman G, Thiruvengadam D. Protective effect of vanillic acid against benzo (a) pyrene induced lung cancer in Swiss albino mice. Journal of biochemical and molecular toxicology. 2019 0ct; 33(10):e22382.

37] Kumnerdkhonkaen P, Saenglee S, Asgar MA, Senawong G, Khongsukwiwat K, Senawong T. Antiproliferative activities and phenolic acid content of water and ethanolic extracts of the powdered formula of Houttuynia cordata Thunb. fermented broth and Phyllanthus emblica Linn. fruit. BMC complementary and alternative medicine. 2018 Dec 1; 18(1):130.

38] Reddy KK, Ravinder T, Kanjilal S. Synthesis and evaluation of antioxidant and antifungal activities of novel ricinoleate-based lipoconjugates of phenolic acids. Food chemistry. 2012 Oct 15; 134(4):2201-7.

39] Vishnu KV, Kumar KA, Chatterjee NS, Lekshmi RG, Sreerekha PR, Mathew S, Ravishankar CN. Sardine oil loaded vanillic acid grafted chitosan microparticles, a new functional food ingredient: attenuates myocardial oxidative stress and apoptosis in cardiomyoblast cell lines (H9c2). Cell Stress and Chaperones. 2018 Mar; 23(2):213-22.

40] Mandras N, Nostro A, Roana J, Scalas D, Banche G, Ghisetti V, Del Re S, Fucale G, Cuffini AM, Tullio V. Liquid and vapour-phase antifungal activities of essential oils against Candida albicans and non-albicans Candida. BMC complementary and alternative medicine. 2016 Dec; 16(1):1-7.

41] Itoh $A$, Isoda $K$, Kondoh M, Kawase M, Kobayashi M, Tamesada M, Yagi K. Hepatoprotective effect of syringic acid and vanillic acid on concanavalin a-induced liver injury. Biological and Pharmaceutical Bulletin. 2009 Jul 1; 32(7):1215-9.

42] Dhananjaya BL, Nataraju A, Gowda CR, Sharath BK, D’souza CJ. Vanillic acid as a novel specific inhibitor of snake venom $5^{\prime}$ nucleotidase: a pharmacological tool in evaluating the role of the enzyme in snake envenomation. Biochemistry (moscow). 2009 Dec; 74(12):1315-9.

43] Maschio BH, Gentil BC, Caetano EL, Rodrigues LS, Laurino LF, Spim SR, Jozala AF, Dos Santos CA, Grotto D, Gerenutti M. Characterization of the effects of the shiitake culinary-medicinal mushroom, lentinus edodes (agaricomycetes), on severe gestational diabetes mellitus in rats. International journal of medicinal mushrooms. 2017; 19(11).

44] Janel N, Noll C. Protection and reversal of hepatic fibrosis by polyphenols. In Polyphenols in Human Health and Disease 2014 Jan 1 (pp. 665-679). Academic Press.

45] Hwang JY, Lin JT, Liu SC, Hu CC, Shyu YS, Yang DJ. Protective role of litchi (Litchi chinensis Sonn.) flower extract against cadmiumand lead-induced cytotoxicity and transforming growth factor $\beta 1$-stimulated expression of smooth muscle $\alpha$-actin estimated with rat liver cell lines. Journal of Functional Foods. 2013 Apr 1; 5(2):698-705.

46] Jiang $\mathrm{R}, \mathrm{Xu} X \mathrm{X}$, Wang $\mathrm{K}$, Yang XZ, Bi YF, Yan Y, Liu JZ, Chen XN, Wang ZZ, Guo XL, Zhao DQ. Ethyl acetate extract from Panax ginseng CA Meyer and its main constituents inhibit $\alpha$ melanocyte-stimulating hormone-induced melanogenesis by suppressing oxidative stress in B16 mouse melanoma cells. Journal of ethnopharmacology. 2017 Aug 17; 208:149-56.

47] Park J, Cho SY, Kang J, Park WY, Lee S, Jung Y, Kang MW, Kwak HJ, Um JY. Vanillic Acid Improves Comorbidity of Cancer and Obesity through STAT3 Regulation in High-Fat-Diet-Induced Obese and B16BL6 Melanoma-Injected Mice. Biomolecules. 2020 Aug; 10(8):1098.

48] Basciano H, Federico L, Adeli K. Fructose, insulin resistance, and metabolic dyslipidemia. Nutrition \& metabolism. 2005 Dec; 2(1):1-4.

49] Vinothiya K, Ashokkumar N. Modulatory effect of vanillic acid on antioxidant status in high fat diet-induced changes in diabetic hypertensive rats. Biomedicine \& Pharmacotherapy. 2017 Mar 1; 87:640-52.

50] Riachi LG, De Maria CA. Yerba mate: An overview of physiological effects in humans. Journal of Functional Foods. 2017 Nov 1; 38:308-20.

51] Ali M, Paul S, Tanvir EM, Hossen M, Rumpa NE, Saha M, Bhoumik NC, Islam A, Hossain M, Alam N, Gan SH. Antihyperglycemic, antidiabetic, and antioxidant effects of Garcinia pedunculata in rats. Evidence-Based Complementary and Alternative Medicine. 2017 Jan 1; 2017.

52] Tlili N, Feriani A, Saadoui E, Nasri N, Khaldi A. Capparis spinosa leaves extract: Source of bioantioxidants with nephroprotective and hepatoprotective effects. Biomedicine \& Pharmacotherapy. 2017 Mar 1; 87:171-9. 